\title{
The Adelaide Meeting of the Australasian Association.
}

THE seventeenth meeting of the Australasian Association for the Advancement of Science was held in Adelaide, South Australia, on August $25-30$ inclusive.

The number of members who attended the meeting is estimated at 750 , and delegates from all the important scientific institutions and societies in Australia and New Zealand were present. The delegates who attended exceeded Ioo in number, and these represented at least fifty institutions, including the Australian National Research Council, the New Zealand Institute, the various State Roval Societies, the various universities both of the Commonwealth and of New Zealand, the Federal and State Government Departments, the British Medical Association, the various mining, engineering, and chemical institutes, together with kindred institutions.

The retiring president, Sir George Knibbs, inducted the president for 1924-26, Sir John Monash, on the evening of August 25. The president's inaugural address on "Power Development" attracted widespread attention throughout Australia and New Zealand.

Prof. G. Elliot Smith, of University College, London, attended the meeting, and assisted Section $F$ (Anthropology) in urging the Federal Government to found an Australian chair of anthropology at the University of Sydney. The Association also supported a resolution of the Australian Universities' Conference to establish a chair of forestry at the University of Adelaide.

The presidential addresses to Sections included the following: A (Astronomy, Mathematics, and Physics), Prof. D. M. Y. Sommerville, "The Development of the Ideas of Space and Time" ; B (Chemistry), Prof. A. C. D. Rivett, "National Research"; B (Subsection Pharmacy), Mr. E. F. Gryst, "Pharmaceutical Progress"; C (Geology and Mineralogy), Dr. H. C. Richards, "Volcanic Activity in Queensland "; D (Zoology), Prof. W. E. Agar, " Some Problems of Evolution and Genetics "; E (Geography and History), Capt. J. K. Davis, " Sailing Directions" ; F (Ethnology and Anthropology), Mr. H. D. Skinner, "Origin and Relationships of the Material Culture and Decorative Art of the Maoris of New Zealand" ; G (Social and Statistical Science), Prof. D. B. Copland, "Monetary Policy and its Reaction upon Australia " ; $\mathrm{H}$ (Engineering and Architecture), Prof. H. E. Whitfeld, "Efficiency in Modern Life" ; I (Sanitary
Science and Hygiene), Dr. J. S. Purdy, "Vitamines and Fruit in Diet" ; J (Mental Science and Education), Mr. J. Nangle, "Vocational Guidance"; K (Agriculture and Forestry), Prof. R. D. Watt, "The World's Food Supply"; L (Veterinary Science), Dr. S. Dodd, "Cancer in Domesticated Animals "; M (Botany), Mr. L. Rodway, "Ecologic Conditions of Vegetation in Tasmania."

A general statement was made by the permanent honorary secretary regarding the pressing needs of the Association, inasmuch as it is coming to be seen that science in Australia and New Zealand needs to extend its usefulness, especially in view of the impetus given to the study of Pacific problems by the recentPanPacific Science Congress, and the Food Conservation Congress, held in Australia and Honolulu respectively. This could be accomplished by the Australasian Association acting as co-ordinator of, and spokesman for, the various divergent interests of scientific and technical societies. In other words, the best work could be done apparently by an affiliation of all the scientific institutions with the Australasian Association for the Advancement of Science, and with the hearty co-operation also of the Australian National Research Council and the New Zealand Institute.

The present machinery of the Australasian Association is too cumbrous for this purpose, and it is found necessary to take a central office in Sydney with an officer in permanent attendance to assist the permanent honorary secretary.

A constitution of few articles is needed with flexible by-laws or regulations to each of the main articles. Continuity of membership is needed, and some permanency also for secretaries of Sections, whereby recommendations to Governments and other authorities might be well considered before presentation.

Perth, Western Australia, was selected as the place of the eighteenth meeting of the Association, the date chosen being August 1926. The president for this meeting will be Sir Thomas R. Lyle. The Government of Western Australia has promised I $200 l$., mainly towards defraying the cost of the publication of the Proceedings.

The nineteenth meeting will be held at Hobart, Tasmania, in January I928, with the promise of financial support from the Tasmanian Government.

E. C. ANDREws.

\section{Preservatives in Food. ${ }^{1}$}

THE report before us contains an account of the preservatives and colouring matters found in different articles of food, together with the Committee's opinion upon the nature and quantities of these substances which should be permissible, taking into consideration, on one hand, their effect upon the body, and on the other, their efficiency in preserving, or making attractive, the different articles of diet in which they are found. Apart from the main body of the report, a series of appendices gives the names of the witnesses examined, and excerpts from the laws of other countries on the use of preservatives and colouring matters in foods, with details as to those which are permissible and which prohibited: one other appendix will be referred to in more detail below.

The principles which guided the Committee in the

1 Ministry of Health. Final Report of the Departmental Committee on the Use of Preservatives and Colouring Matters in Food. Pp. 84. (London: H.M. Stationery Office, I924.) Is. 6 d. net. interim report on the use of preservatives in meat, which have already been noticed in these columns (NATURE, September 2o, p. 448), are emphasised again in the report under consideration. Since the ideal of the consumption of fresh food alone is impracticable of attainment under modern conditions of civilisation, and cold transport or sterilisation by heat may be unsuitable processes in certain cases, the only course open is to use some preservative, and the Committee has devoted considerable attention to the question as to which preservatives are the least likely to be harmful to the individuals consuming them in small quantities, although often over long periods of time, and yet are reasonably efficient in preventing decomposition or other change in the food or drink product. In certain cases, preservatives have a further disadvantage in that their addition may give a sense of false security and encourage slackness in the preparation of the food: in other cases their use seems to have become a habit

NO. 2876 , vOL. I I 4 ] 
with some of the manufacturers of certain articles of food, such as pickles, since others do not use them at all.

The report considers first the different substances which have been used as preservatives and their effect upon the human economy; they can be divided into three groups. In the first are hydrofluoric acid, its salts and derivatives (seldom if ever used at the present time), and formaldehyde and its derivatives. The effects of the latter have been already mentioned in the account of the Committee's Interim Report and will not be further considered here. It is sufficient to state that in the opinion of the Committee, with which we are in complete agreement, the substances in this group should be completely prohibited in articles of diet. In the second group are placed boron preservatives and salicylic acid and its salts: these should also be prohibited. Although this conclusion may cause some surprise, the evidence in favour of it is remarkably strong. In the first place, both boric and salicylic acids act as irritants to the alimentary tract; the former, moreover, is only excreted slowly after absorption, so that its action is cumulative. Boric acid or its salts are used at present very largely in cream, butter, liquid eggs, margarine, and potted meats, or dusted over bacon and hams exported to Great Britain: but since these products are frequently sold without the addition of preservatives, it appears quite possible to dispense with them, providing methods of preparation and conditions of transport are satisfactory. This conclusion is strengthened by the fact that at the present day the milk supply is satisfactorily maintained although the addition of preservatives is forbidden, a state of affairs which, twenty-five years ago, was considered to be impossible of achievement in some quarters. As regards salicylic acid, which is used chiefly in beverages, benzoic acid has about the same effectiveness as a preservative and is less irritant to the stomach, and is therefore preferable.

The third group comprises the least harmful of the preservatives in benzoic acid, sulphurous acid, and their salts: the report gives a list of the foods and beverages in which they may be permitted, together with the maximum amounts allowable. Sulphur dioxide may be permitted in sausages, jam, dried and preserved fruits, beer and cider, and wines, cordials, and fruit juices, in amounts of a few grains per pound or pint. Benzoic acid should be allowed only in the following beverages: coffee extract, nonalcoholic wines and cordials, and sweetened mineral waters and ginger-beer.

Turning to the question of colouring matters, the Committee advises the prohibition of the use of copper sulphate as an agent for preserving the colour of green vegetables. They consider that this will not affect the sale of canned vegetables, seeing that peas canned without the use of copper find a ready sale in Great Britain. As regards other colouring matters, a few pigments containing iron and some natural organic colours such as gamboge, saffron, caramel, and cochineal are considered harmless : but of the synthetic aniline dyes, relatively few have been considered harmless in other countries, and the Committee recommends that a list of those permitted should be drawn up by the Minister of Health: this is necessary, since many of these dyes are potent antiseptics in dilute solutions; moreover, they cannot be grouped in classes, since a harmful product may be closely related to one that is quite innocuous.

Finally, the report considers the best method of making its conclusions effective : among its recommendations here is one that the amount of preservative or nature of colouring matter permitted should be definitely laid down by law, and another that the processes of preparation of food for human consumption should be under closer control. In this connexion, improved methods and facilities of transport and storage are urgently required. In one of the appendices is given an interesting example of the co-operation of a trade in reducing the amount of preservative present in a food, by its members agreeing not to use the article containing it in certain types of foodstuffs prepared by them. The report should do much to raise the standard of preparation of food in Great Britain.

\section{Works of Early Man in East Anglia.}

$\mathrm{A}^{\mathrm{T}}$

the autumn meeting of the Prehistoric Society of East Anglia, held at the rooms of the Geological Society, Burlington House, London, on November I2, Mr. R. A. Smith, and afterwards the president, Mr. Henry Balfour, in the chair, special reference was made to the loss sustained through the death of the late Mr. E. T. Lingwood, of Westleton, who, in addition to great abilities and enthusiasm as a practical excavator and collector of flint implements, had for years done very valuable voluntary work by drawing large numbers of the specimens selected for illustration in the annual Proceedings of the Society. Had Mr. Lingwood lived, a proposal to offer him honorary membership of the Society would have been brought forward at the next annual meeting, and it was unanimously resolved by the London meeting that this distinction should be offered to Mrs. Lingwood, together with an expression of the sympathy of the members of the Society.

An important announcement concerning the protection of Grime's Graves, Norfolk, as a national monument was made by the hon. secretary, Mr. G. Maynard, of the Ipswich Museum, who stated that H.M. Office of Works has accepted a suggestion made on behalf of the Society and has taken steps to include in the schedule a considerable area of the open warren which borders the well-known group of ancient flint mines on the Weeting Hall estate. The additional area includes the sites of the recently discovered pits on the slopes of the Grime's Graves ridge which are being investigated by Mr. A. L. Armstrong.

It was also announced that with the approval of the Office of Works, the owner of the estate has given permission for the erection of a shelter over the mouth of the pit cleared out by the Society in I9I4 and subsequent years. This protection is designed to prevent the silting up of the entrance to the galleries at the bottom of the pit, and to facilitate entrance to the old mine workings. The delimitation of a footpath across the warren to the site has also been agreed to. Information as to the probable cost of the shelter is being obtained, and the council of the Society is shortly to be asked to consider the question of taking up the scheme.

Mr. J.P.T. Burchell described some stratified finds on the North Kent coast, where the peculiar elongated flint implement known from its abundance in the bed of the Thames as the "Thames pick," is found in plenty at the foot of the cliffs but is without a definite geological horizon. The cliffs examined are at Bishopstone near Reculver, and Hampton near Herne Bay. At the former site, hand-axes of Chelles and St. Acheul type have been found in the ochreous gravel which is capped by brick earth, with Neolithic flakes and cores in its upper levels.

Sunk in the top of the brick earth and adjoining

NO. 2876 , VOL. I I 4 ] 